\title{
Numerical modeling of gas infrared heating of production buildings
}

\author{
Anton N. Ermolaev ${ }^{1, *}$ \\ ${ }^{1}$ Tyumen industrial University, 625000 Tyumen, Russia
}

\begin{abstract}
The paper presents the method of simulating the infrared heating of a ventilated room based on the finite element analysis (FEM) with application of the engineering software. Approbation of the method was carried out by studying the influence of various parameters of infrared gas radiators on the temperature distribution in the volume of industrial facility. Analysis of the obtained data indicates that high-temperature gas-fired infrared heating system produces significant thermal radiation in the upper zone of the computational domain by the heated surfaces with simultaneous flow of convective heat and mass transfer processes. Temperature difference between the working area and the ceiling space varies from $17^{\circ} \mathrm{C}$ to $65.2^{\circ} \mathrm{C}$. The obtained results confirm the applicability of the engineering software ANSYS Multiphysics for modeling the combustion process and the heat and mass transfer in solving problems of designing and optimizing hightemperature gas infrared heating systems.
\end{abstract}

\section{Introduction}

Designing a gas infrared heating system is a complex engineering practice. It includes solving the thermal balance of a radiant heating system, selecting heating devices by type of execution and heat output, determining the optimal locations for gas infrared radiators in the room, selecting regulating equipment, satisfaction of the received heat load with sanitary and hygienic requirements $[1,2]$.

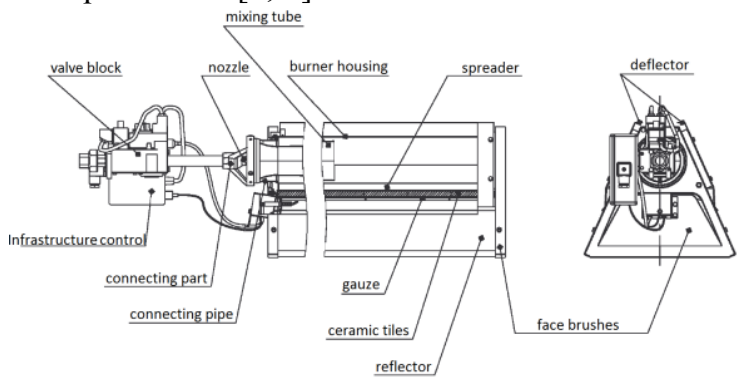

Fig. 1. Scheme of a typical high-temperature gas infrared radiator.

${ }^{*}$ Corresponding author: ermolaevanton03@gmail.com 
The difficulty is in the fact that there is currently no single standard methodology for the design and calculation of gas infrared heating systems. The current normative and technical documentation provides only regulation of indoor air temperature, taking into account heat losses through the enclosing structures and heat consumption for air heating [1-4]. However, it does not fully account all the specifics of radiation heating systems. For example, an excessive number of gas infrared radiators (Fig. 1) and their incorrect placement lead to increased operational costs and a violation of the irradiation requirements. "Despite the fact that high-temperature gas infrared radiators have high energy efficiency, during their operation for heating large-scale production buildings a number of drawbacks was discovered: upper zone was overheated; smut appeared on walling surface resulting in wall subsequent destruction" [5]. Listed drawbacks are caused by energy losses in stack (24-30\%) and by high-temperature gas infrared radiator's casing (9-18\%).

In the 21 century, the best methods of mathematical modeling became available to a wide range of researchers in the form of commercial software products. Among the software products, the most common, authoritative and proven tool is Ansys Multiphysics, which uses approved mathematical models and discretization of the computational domain using the finite element method to solve the problems of heat and mass exchange and combustion modeling.

The gas infrared heating system includes a lot of variable parameters: the geometric dimensions, shapes and materials of all elements of the system, the optical properties of the environment, the location of the emitters and their design. Therefore, in order to work out the methodology for designing the gas infrared heating system, numerical modeling was carried out with changing the boundary conditions.

\section{Computational model}

The differential equations of computational model with the following boundary conditions were solved. Natural gas with the density $0.784 \mathrm{~kg} / \mathrm{m} 3$ and calorific value $37.26 \mathrm{MJ} / \mathrm{kg}$ was set as the fuel. Oxidizer was air with oxygen mass fraction of 0.23 . Gas-fired infrared radiators with thermal capacity of $5,10,15,20,30,40 \mathrm{~kW}$ were studied. Thermal capacity of infrared radiators was defined by varying the number of ceramic tiles (see fig. 1), $1.5 \mathrm{~kW}$ each; fuel consumption per tile was $0,5 \mathrm{~m} 3 /$ hour. Wall material was sandwich panels with polyurethane foam insulation. The material of the light opening is glass with the thickness of $0.27 \mathrm{~m}$. The internal emissivity of the inner enclosing surfaces is assumed to be $\varepsilon=0.8$. On the walls that bound the calculated region, heat exchange conditions of the third kind are given. The outside temperature was minus $35^{\circ} \mathrm{C}$. The ventilation was organized as follows: air supply in the lower zone of the room, and air intake in the upper zone. The most common gas infrared heating system layouts were considered: industrial facility with dimensions of $60 \mathrm{~m} \times 24 \mathrm{~m} \times 12 \mathrm{~m}$ with high-temperature radiators of thermal capacities of $5,10,15,20,30,40 \mathrm{~kW}$ at hanging heights from 4 up to 10 meters. We carried out a series of numerical experiments to obtain temperature fields formed in the area above hightemperature gas-fired infrared emitter's installation.

The computational domain of high-temperature gas infrared radiator is a conjugate gasdynamic zone with double walls at the points of contact. With the help of a grid generator, the computational volume is divided into tetrahedral finite elements. Trial calculations using grids with different topologies and the number of cells showed that the mesh adopted in this work, containing about $3 \cdot 10^{5}$ control volumes, provides a low sensitivity of the results to further grinding the mesh. The finite element grid of the high-temperature gas infrared heating system is shown on Fig. 2. A standard mathematical k- $\varepsilon$ model is chosen to model the turbulence described in paper [6]. Calculation of radiant heat exchange was 
performed using the Discrete Ordinates radiation model described in paper [5]. To describe the ongoing chemical reaction, a kinetic model of laminar combustion was adopted. The reliability of the selected mathematical models is confirmed by field trials [ $5-8]$.
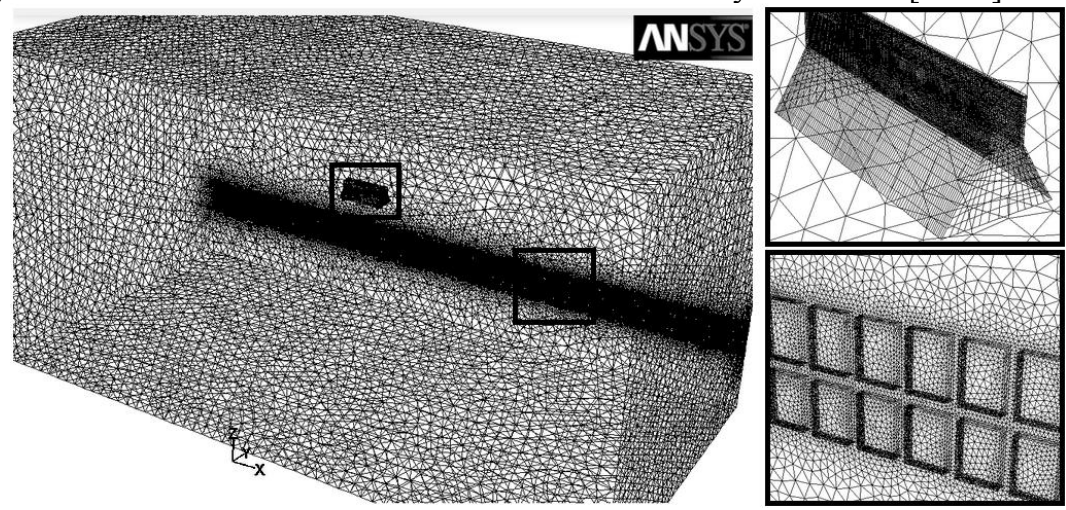

Fig. 2. Computational mesh of high-temperature gas-fired infrared heating system.

\section{Results of the study}

Analysis of the obtained data indicates that high-temperature gas-fired infrared heating system produces significant thermal radiation in the upper zone of the computational domain by the heated surfaces with simultaneous flow of convective heat and mass transfer processes. According the results of the simulation (Figure 3), the temperature difference between the working area and the ceiling space varies from $17^{\circ} \mathrm{C}$ (the gas infrared radiators were placed at a height of $4 \mathrm{~m}$ ) to $65.2^{\circ} \mathrm{C}$ (the gas infrared radiators were placed at a height of $10 \mathrm{~m}$ ).

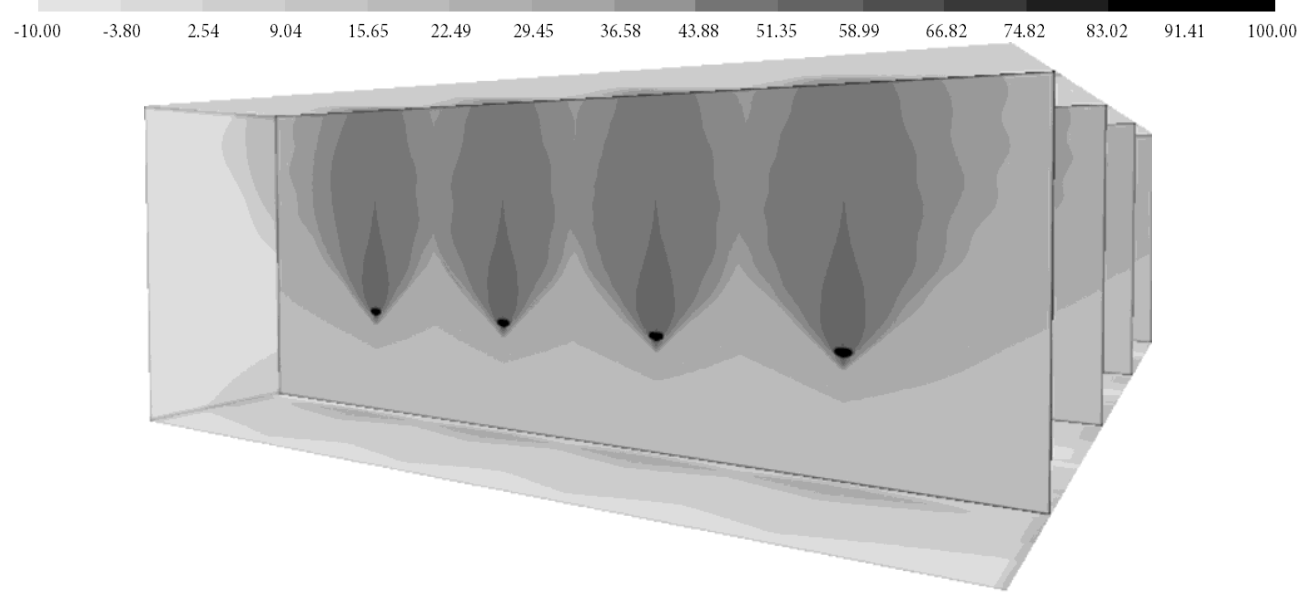

Fig. 3. Temperature distribution above high-temperature gas-fired infrared emitters.

The maximum value of the temperature was observed above the gas infrared radiators, then the temperature is decreased inversely proportional to the square of the distance from the radiator. Isolines of temperature have a V-shaped closed contour (fig. 3), increasing the curvature with temperature.

\section{Conclusion}


The results of research and mathematical modeling were:

1. Effective use of infrared heating systems is a multiparameter task that requires the effective development of formalized optimization procedures.

2. We have developed method of simulating the infrared heating of a ventilated room based on the finite element analysis (FEM) with application of the engineering software.

3. Approbation of the method was carried out by studying the influence of various parameters of infrared gas radiators on the temperature distribution in the volume of industrial facility.

4. The obtained results confirm the applicability of the engineering software ANSYS Multiphysics for modeling the combustion process and the heat and mass transfer in solving problems of designing and optimizing high-temperature gas infrared heating systems. It should be noted that approaches similar to the one proposed have not previously been applied to the analysis of the microclimate of industrial facilities.

\section{References}

1. Sanitary rules and regulations 2.2.4.548-96. 2.2.4 Physical factors of the production environment. Hygienic requirements for the microclimate of production facilities (Information and Publishing Center of the Ministry of Health of Russia, Moscow 1997)

2. Code of Regulations 60.13330.2012. Heating, ventilation and air conditioning (Ministry of Regional Development of Russia, Moscow 2012)

3. A. V. Kazakov, R. B. Tabakaev, P. Y. Novoseltsev, A. V. Astafev, A.V., MATEC Web Conf., 19, 01014 (2014)

4. A.I. Bogomolov, D. Ya. Vigdorchik, M.A. Maevsky, Gas burners of infrared radiation and their application (Stroiizdat, Moscow, 1967)

5. A. N. Ermolaev, S. A. Khaustov, EPJ Web Conf., 110, 01038 (2017)

6. S. A. Khaustov, A. S. Zavorin, K. V. Buvakov, L. D. Kudryashova, A. V. Tshelkunova, EPJ Web Conf., 82, 01041 (2015)

7. S. A. Khaustov, A. S. Zavorin, K. V. Buvakov, V. A. Sheikin, EPJ Web Conf., 82, 01039 (2015)

8. S. A. Khaustov, Y. A. Belousova, K. V. Buvakov, A. Y. Dolgih, R. N. Kulesh. Proc. of 11th International Forum on Strategic Technology (IFOST - 2016), 2, 548-551 (2016) 